\title{
Saúde mental e web rádio: processo de inclusão digital
}

\author{
Mental health and web radio: digital inclusion process \\ La salud mental y la radio web: proceso de inclusión digital
}

\author{
DEISE JULIANA FRANCISCO* \\ RAFAEL ANDRÉ DE BARROS**
} \begin{abstract}
$\diamond$
RESUMO - O artigo problematiza o uso de oficinas de web rádio na saúde mental, desde o ponto de vista da inclusão digital e da atuação do pedagogo. Trata-se de uma pesquisa-intervenção realizada em conjunto com usuários de um Caps (Centro de Atenção Psicossocial) do município de Maceió. Como instrumento de coleta de dados foram utilizados diário de campo, entrevista semiestruturada com equipe do Caps e observação dos usuários. A partir da literatura sobre tecnologia e habilitação psicossocial foram realizadas oficinas. Dentre os resultados, apresenta-se de maneira positiva o processo de habilitação social e inclusão digital no coletivo com a produção web radiofônica. $\mathrm{O}$ produto final não foram os programas, mas a redescoberta da autonomia, o processo de ensino e aprendizagem para utilização dos recursos informatizados e o processo de inclusão digital. A web rádio contribui de forma significativa para a promoção da saúde mental, destacando-se como um recurso no processo de habilitação social de sujeitos em sofrimento psíquico.
\end{abstract}

Palavras-chave - Saúde mental. Reabilitação psicossocial. Inclusão digital.

\begin{abstract}
The paper discusses the use of workshops webradio in mental health from the point of view of digital inclusion and the role of educator. It was an intervention research conducted in conjunction with users of a Caps (desdobrar a sigla) in the city of Maceió. As an instrument for data collection field diary, semistructured interviews with the Caps staff and observation of users were used. From the literature on technology and psychosocial empowerment workshops were held. Among results, is presented in a positive manner the process of enabling social and digital inclusion in the collective with the web radio production. The final product was not the programs, but the rediscovery of autonomy, the process of teaching and learning resources for use of computerized and digital inclusion. The webradio contributes significantly to the promotion of mental health, highlighting as a resource in social empowerment of individuals in psychological distress process.
\end{abstract}

Keywords - Mental health. Psychosocial rehabilitation. Digital inclusion.

RESUMEN - En el documento se analiza el uso de talleres webradio en la salud mental desde el punto de vista de la inclusión digital y el papel del educador. Fue una investigación de la intervención llevada a cabo en colaboración con los usuarios de un Caps (desdobrar a sigla) en la ciudad de Maceió. Como instrumento para el diario de campo de recolección de datos, se utilizaron entrevistas semi-estructuradas con el personal del Caps y la observación de los usuarios. A partir de la literatura sobre los talleres de tecnología y empoderamiento psicosocial se celebraron. Entre los resultados, se presenta de una manera positiva el proceso que permite la inclusión social y digital en el colectivo con la producción de radio web. El producto final no era de los programas, pero el redescubrimiento de la autonomía, el proceso de los recursos de enseñanza y aprendizaje para el uso de la inclusión computarizado y digital. La webradio contribuye significativamente a la promoción de la salud mental, destacando como un recurso en el empoderamiento social de las personas en proceso de angustia psicológica.

Palabras clave - Salud mental. Rehabilitación psicossocial. La inclusión digital.

\footnotetext{
*Doutora em Informática na Educação pela Universidade Federal do Rio Grande do Sul (Porto Alegre, RS, Brasil) e professora na Universidade Federal de Alagoas (Maceió, AL, Brasil).E-mail: < deisej@gmail.com>.

** Mestre em Educação pela Universidade Federal de Alagoas (Maceió, AL, Brasil) e professor na Universidade Estadual de Ciências da Saúde de Alagoas (Maceió, AL, Brasil).E-mail: <rafa.admufal@hotmail.com>.
} 
Este artigo advém de uma dissertação de mestrado que teve como premissa a constituição de espaços para vivência e trocas dos usuários em sofrimento psíquico com as tecnologias da informação e comunicação (TIC), em especial, blog e web rádio, na perspectiva da inclusão digital (BARROS, 2012), e de um Trabalho de Conclusão de Curso que enfatizou a atuação do pedagogo na saúde mental. Parte de dados da dissertação e de discussões do TCC para discutir a inclusão digital na relação com as aprendizagens realizadas na oficina informatizada. Tem como objetivos analisar a produção web radiofônica quanto à inclusão digital e a relação dos usuários de saúde mental com os artefatos de web rádio, bem como a atuação do pedagogo nesse contexto.

Pensar em saúde mental implica analisar a condição dos humanos e cidadãos. Desde a vigência da Lei da Reforma Psiquiátrica no Brasil, intensifica-se a criação de serviços substitutivos ao manicômio, com o fortalecimento do sistema de saúde em termos de serviço público. Nesse sentido, vários dispositivos foram pensados e desenhados, desde os mais frequentes como os Caps até as iniciativas de promoção de educação, cultura, moradia e trabalho. Parte-se do pressuposto de que saúde mental não é apenas uma questão de saúde, ou mesmo de saúde pública. É uma questão de educação e cultura também. É desde essa perspectiva que se avizinha a intervenção em saúde mental, nos serviços substitutivos ao manicômio.

Nessa busca, interessa aqui trazer as tecnologias digitais como parceiras para a reinserção psicossocial, como um operador de abertura e de conexões no território subjetivo. Assim, problematizar a inclusão digital no Brasil e sua relação com a intervenção em saúde mental merece atenção na perspectiva também de que o acesso à informação é um dos direitos constitucionais garantidos.

As tecnologias são artefatos considerados em sua história e em sua relação com o social. Intimamente vinculadas com os modos de ser e de existir, são uma construção humana:

Somos capazes de criar seres técnicos, porque temos dentro de nós mesmos um conjunto de relações e uma associação matéria-forma que é notavelmente semelhante ao que nós estabelecemos no objeto técnico. A relação entre o pensamento e vida é análoga à relação entre um objeto técnico estruturado e o ambiente natural. O objeto técnico é um objeto individualizado, é um objeto inventado, produto do jogo de causalidades entre vida e pensamento no homem (SIMONDON, 1980, p. 66).

Em anos recentes, a integração das diversas TICs tem se apresentado como alternativa no processo de reabilitação social de sujeitos em sofrimento psíquico, tornando-se parte de um processo dinâmico, interativo e inclusivo utilizado, principalmente, no serviço substitutivo - Caps. Diversas interfaces de comunicação e informação têm sido experenciadas e sugeridas em pesquisas na intervenção em saúde mental (COSTA e CARVALHO, 2003; FRANCISCO, 2007), apontando novos caminhos que visam a agregar valor social e inclusivo, e um aspecto dinâmico e interativo na prática terapêutica em oficinas.

Assim, para utilizar determinada tecnologia, deve haver a apropriação, não de forma instrumental, mas de maneira que o sujeito saiba utilizá-la para intervir em sua própria vida, em sua realidade e nos cenários em que atua. Pesquisas (STREPPEL, 2010; BITTENCOURT, 2012) apontam para a necessidade dessa apropriação. Daí trabalharem com aplicativos digitais que proporcionam a esses usuários se apropriarem significativamente dos dispositivos nos Caps, na perspectiva da inclusão digital.

De fato, o processo de reabilitação social não apenas perpassa a questão da inclusão digital, mas também o processo de aprender a conviver em coletividade, a lidar com os próprios anseios e vicissitudes, e desenvolver a autonomia e o protagonismo social. Ainda apoiando essa linha de ação, Bittencourt (2012) afirma que o processo de habilitação social pode e deve ser construído a partir do viés da democratização da imersão nas TICs, por intermédio do processo de ensino e aprendizagem, visando à transformação social.

Com relação aos Caps, locais em que será discutido o processo de inclusão digital, o trabalho é desenvolvido por equipe multiprofissional, composta por profissionais de nível médio e superior, podendo atuar também o pedagogo. $\mathrm{O}$ atendimento varia do trabalho individual, em grupo, com as famílias, às atividades comunitárias. Passam a existir nesses espaços práticas clínicas, pedagógicas e sociais, e o pedagogo pode assim ser inserido na realização destas e assumir a função de desenvolver atividades voltadas para a inserção do usuário na sociedade. E, dessa forma, proporcionar-lhe a integração, intervindo na construção de sua autonomia e independência. Esse profissional, por sua vez, pode construir condições para que o sujeito tenha uma vida de qualidade e, ao mesmo tempo, ajudá-lo a organizar-se e aprender a lidar melhor com seus conflitos. Há vários elementos que contribuem para um melhor resultado do trabalho, utilizando por base os preceitos da Reforma Psiquiátrica e os objetivos dos Caps.

A parceria com a família é fundamental para o avanço no tratamento do usuário e assume base legal, por meio do inciso VII das Diretrizes Curriculares Nacionais para o Curso de Graduação em Pedagogia, Licenciatura (BRASIL, 2006), no momento em que se afirma que esse profissional deve ser promotor e facilitador das relações cooperativas entre a instituição educativa e a família. Nessa perspectiva, o pedagogo deve trabalhar e estimular 
sua inclusão para que possa formar uma parceria colaborativa na ação do resgate social desses indivíduos.

Outra função do pedagogo que exerce seu trabalho no Caps é pesquisar o envolvimento do sujeito com a comunidade, família, meio social e possibilitar estratégias para uma melhor aproximação deste com a sociedade. Assim, é fundamental conhecer o usuário, ou seja, seus projetos, suas habilidades e, o mais importante, despertar nele o desejo de continuar, de viver. O papel do pedagogo torna-se essencial para a promoção da saúde mental do sujeito e para sua reinserção social, embasando-se no inciso IX, das diretrizes do curso de Pedagogia (BRASIL, 2006). Estas ressaltam a necessidade das capacidades investigativas e integrativas desse profissional, para contribuir na superação de possíveis exclusões. Assim como no inciso II, do artigo $2^{\circ}$ da Lei da Reforma Psiquiátrica (BRASIL, 2001), que trata do direito do usuário de ser tratado com humanidade e respeito, visando a sua recuperação pela inserção na família, no trabalho e na comunidade.

Articulada com a atual proposta de atenção à saúde mental no Brasil - que busca desinstitucionalizar e incluir pessoas em sofrimento psíquico nos diferentes espaços da sociedade -, a atuação do pedagogo pode ser bem-vinda. Intenta-se potencializar a rede para ofertar processos facilitadores aos usuários com determinadas limitações, atuando na restauração dos exercícios de sua autonomia. Para tanto, enfatizam-se as habilidades do indivíduo, "mediante uma abordagem compreensiva e um suporte vocacional, residencial, social, recreacional, educacional, ajustados às demandas singulares de cada indivíduo e cada situação de modo personalizado" (PITTA, 1996, p. 20).

Outro fator essencial para o trabalho do pedagogo são as oficinas, que estão entre as atividades que podem ser realizadas por ele e são ferramentas fundamentais para a promoção da aprendizagem e desenvolvimento do usuário que se encontra em um hospital psiquiátrico ou no Caps. Por exemplo, o pedagogo pode desenvolver oficinas de alfabetização que proporcionam a esse usuário a inserção no mundo letrado, uma vez que a maioria das pessoas que frequentam esses serviços não teve acesso à escola e encontra nesse espaço uma oportunidade de conhecer e desenvolver sua linguagem, relações matemáticas, exploração e conhecimento de mundo. O pedagogo tem, portanto, o papel de intervir em seu processo educacional, assumindo assim uma proposta de inclusão, pois pode estimular o interesse do usuário pelos estudos, possibilitando uma possível entrada na escola regular. Isso porque lhe apresenta o conhecimento letrado e mostra que ele é capaz de aprender e de avançar. Assim, passa a realizar um trabalho socioeducativo, visando à promoção das habilidades e formação do sujeito, ao mesmo tempo em que reforça o caráter de intencionalidade educativa.
Comprova, então, que para existir uma pedagogia não é preciso que se fique preso às paredes da sala de aula. $O$ pedagogo pode trabalhar diversos outros temas nas oficinas, desde que estes tenham sempre o objetivo de explorar as habilidades do paciente e de integrá-lo à vida em sociedade.

\section{INTEGRAÇÃo DO RÁDIO AO PROCESSO DE REABILITAÇÃO SOCIAL EM SAÚDE MENTAL}

A partir da última década, a transmissão radiofônica foi incorporada ao âmbito da saúde mental como parte do processo terapêutico, por intermédio de oficinas, na reinserção social de sujeitos com sofrimento psíquico. Identificam-se, no Brasil, espaços que promovem ações para habilitação social de pessoas em sofrimento psíquico. São utilizadas as TICs nas práticas terapêuticas expressivas de inclusão como mediadoras no processo de reinserção desses sujeitos no cotidiano da vida em sociedade. Alguns projetos destacam-se como precursores na proposta de fazer rádio em saúde mental, com notórias experiências na integração dessa interface como recurso terapêutico no processo de habilitação social de sujeitos em sofrimento psíquico. Nelas, usuários e profissionais da saúde mental permitem-se experenciar novas práticas e posturas como protagonistas e criadores de sua própria produção.

Para Teixeira (2010), a inclusão digital necessita de acesso e produção de informações na internet pelos internautas, sendo necessário também um processo de ressignificação da inclusão digital “(...) que tenha como base e finalidade a construção e a vivência de uma cultura de rede como elemento fundamental para o exercício da cidadania (...) diante de uma sociedade globalizada e conectada" (2010, p. 41). Ou seja, para ocorrer inclusão digital, é preciso haver significação da produção e não mero uso dos computadores.

A primeira experiência do uso do rádio no processo de habilitação psicossocial remonta ao ano de 1989, bem antes da Lei 10.216/01, e ocorreu quando a administração pública municipal de Santos, São Paulo, decretou intervenção na Casa de Saúde Anchieta (STREPELL, 2010). Dessa feita, criou-se a Rádio Tam Tam para veiculação do projeto que era feito pelos próprios usuários.

Cita-se também o programa de rádio Maluco Beleza, que teve início em 1995, sendo remodelado, e a Rádio 12, com o objetivo de ser instrumento mediador da habilitação psicossocial dos usuários do serviço e atuar no caminho da desospitalização, da participação social dos usuários e do respeito ao direito à convivência dos diferentes (ROLDÃO e MOREIRA, 2007). O programa de rádio De Perto Ninguém é Normal, na cidade de Santa Maria/RS, é produzido exclusivamente por usuários do 
Caps e tem entre seus objetivos a busca pela recuperação terapêutica e o estabelecimento das redes sociais (STREPELL, 2010). Sua grade de programação inclui entrevistas, quadros musicais, humor, radionovela, poesia e variedades. O Coletivo de Rádio Potência Mental teve início em 2006 e foi inspirado na experiência da Rádio Nikosia, de Barcelona (GORCZEVSKI, PALOMBINI e STREPPEL, 2009).

Essas foram e/ou são "precursoras" da experiência de fazer rádio em saúde mental no Brasil, criando e potencializando espaços de intersecção entre a academia e a rede de atenção à saúde mental. Na medida em que priorizam o habilitar de pessoas em sofrimento psíquico ao ato criativo e protagonista que está envolvido na criação, edição e transmissão radiofônica. Essas experiências possibilitaram o conhecimento de outras perspectivas de aplicabilidade do rádio na habilitação social de muitos usuários do Caps, assim como outras maneiras de tornar esse espaço mais atrativo. De igual modo, podem fornecer "subsídios para a inclusão de tecnologias de informação e comunicação na formulação e implementação de políticas de saúde e comunicação, tendo como perspectiva um alargamento das potências de vida na cidade" (GORCZEVSKI, PALOMBINI e STREPPEL, 2009, p. 6).

\section{Metodologia}

$\mathrm{O}$ estudo consistiu numa pesquisa com abordagem qualitativa, do tipo de pesquisa-intervenção, que se baseia na multiplicidade e no potencial dos encontros, na produção de acontecimentos, de invenção e de experimentação (PAULON, 2005), havendo inseparabilidade entre conhecer e agir, entre produzir conhecimento e produzir efeitos no social (BARROS e PASSOS, 2000). Esta favorece uma metodologia coletiva, a discussão e a produção coletiva, podendo estimular processos de autonomia e protagonismo com usuários do Caps.

Francisco (2007) afirma que a utilização de oficinas em saúde mental nos serviços substitutivos possibilita atividades e produções como vias de reconhecimento das potencialidades dos participantes de protagonizarem perante sua família, equipe de saúde mental e outros sujeitos sociais. Delgado, Leal e Venâncio (1997) encaram a oficina sob três perspectivas de intervenção em saúde mental: Espaço de Criação, Espaço de Atividades Manuais, Espaço de Promoção de Interação. Lappann-Botti (2004) acrescenta que os fatores de unificação das experiências intituladas "oficinas" não se referem aos tipos de atividades desenvolvidas, mas à noção que se tem desse espaço como um elemento "facilitador da comunicação e das relações interpessoais, favorecendo deste modo a interação, a integração e a reinserção social" (p. 51).
O estudo foi desenvolvido nas dependências do Caps Dr. Rostan Silvestre, localizado no município de Maceió/AL. As oficinas aconteceram com frequência semanal e contaram com a participação de bolsistas graduandos em Psicologia e Pedagogia, além da assistente social do Caps e do proponente desta pesquisa. Os grupos fomentaram os momentos práticos de produção por meio da gravação e edição dos conteúdos, sempre no sentido da interação com o computador. Foram coordenados pelo pesquisador deste estudo, permitindo-se que os usuários e a equipe interagissem entre si e com os dispositivos digitais. A proposta consistia em que esses conteúdos fossem transmitidos de maneira síncrona e/ou postados para serem acessados de maneira assíncrona pela rádio do projeto instalada no blog do projeto (http://www. criandolacos.blogspot.com).

As oficinas terapêuticas informatizadas se constituíram em momentos de interação com o computador e de criação dos programas em áudio. Recursos como notebook com sistema operacional Windows 7, microfone, fone de ouvido, software Audacity estavam sempre à disposição dos usuários nas oficinas. Foi realizado um total de 12 encontros, com oficinas de técnicas básicas de produção e transmissão em rádio.

A partir da produção radiofônica, a pesquisa tem como premissa despertar a capacidade criativa dos usuários, criando espaços de interação entre si, espaços de socialização de suas produções com a família, profissionais do Caps, academia e com demais componentes da sociedade. Não são as produções em áudio o produto final, mas o desenvolvimento das capacidades cognitivas, de sociabilidade, de autonomia e de protagonismo de sua própria existência.

Os sujeitos da pesquisa foram quatro usuários escolhidos pela equipe do Caps, conforme Plano Terapêutico Individual e número disponível de equipamentos. Participaram duas usuárias e dois usuários, com idades entre 21 e 34 anos, a assistente social da equipe do Caps e a equipe do projeto - dentre tal equipe, destaca-se a participação de estudante de Pedagogia. Para fins de produção de dados, foram utilizados observação participante, entrevistas semiestruturadas e diários de campo. As oficinas foram realizadas com frequencia semanal, informatizadas, num total de 12 .

A pesquisa foi aprovada pelo Comitê de Ética em Pesquisa da Universidade Federal de Alagoas (Ufal) sob protocolo de no 010113/2011-25.

\section{RESULTADOS E DISCUSSÃo}

Para a produção da rádio foram utilizados três softwares básicos de edição, reprodução e transmissão de conteúdos em áudio: Audacity (editor de áudio), Zararádio 
(automação de emissões de conteúdos em áudio) e Edcast (decodificador de áudio). O servidor gratuito utilizado foi o do projeto Dissonante (http://dissonante.org). Estava construída a rádio e o servidor já se achava ativo. $\mathrm{O}$ canal para divulgar a rádio e as produções do projeto foi o $b l o g$ $<$ http://criandolacosufal.blogspot.com.br $>$.

A produção deste se deu em conjunto com toda a equipe. Uns se encarregaram da criação, outros da edição, e todos pensaram nas postagens e no projeto gráfico. Os usuários escolheram a imagem de um quebra-cabeça com cores diferentes, mas que se integram para formar um todo. O site ganhou o nome do projeto Criando Laços, e a ideia do quebra-cabeça unido e com cores diferentes cumpriu a função de demonstrar ligações. O layout com o nome do blog ficou na fonte que parece com uma série de cordas entrelaçadas e que, juntas, formam o nome Criando Laços. Sendo que a ideia da corda entrelaçada complementa o sentido de laços, protagonizado pelos usuários.

As oficinas ocorreram no projeto de extensão Criando Laços Via Recursos Informatizados, no Caps Dr. Rostan Silvestre, que teve dois eixos: um que tratou da produção em blog e outro que atuou com rádio. Ambos foram realizados em conjunto, em dias alternados, mas em consonância com a proposta de um objetivo único: gerar no Caps um espaço para o processo de protagonismo e autonomia dos usuários, tendo como meio as oficinas com dispositivos das TICs, na perspectiva da inclusão digital.

O primeiro contato teve por objetivo conhecer o grupo e suas respectivas realidades. Isso ocorreu em rodas de conversa, e todos foram incentivados a narrar suas histórias de vida e o que os trazia ao Caps e àquelas oficinas. Os próprios usuários indicaram de que forma poderiam contribuir com as oficinas. Foram verificados os interesses, habilidades, objetivos e aptidões que pudessem auxiliar nas atividades.

Nesse primeiro momento, um usuário, de nome Adele $^{1}$, afirmou que utilizava computador no seu dia a dia. Ele (ou ela?) usava um computador exclusivo e passava boa parte do dia em redes sociais, ouvindo e baixando músicas. Outra usuária, de nome Maria, disse que em sua residência havia um computador, mas a família lhe negava acesso por temer que este fosse danificado. Uma terceira usuária, de nome Sofia, revelou não possuir computador em casa e que, às vezes, usava a lan house como ponto de acesso. Um quarto usuário, de nome Hades, não possuía computador em casa e também costumava utilizar-se de uma lan house. Acrescentou que ao informar a um parente sobre o início das oficinas, este se prontificou a lhe presentear com um notebook.

Todos possuíam algo em comum: o desejo de interagir com o computador e descobrir as possibilidades de uso desse recurso na produção da rádio. Buscou-se identificar os gostos e as aptidões iniciais dos usuários, e logo foi definida a contribuição que cada um poderia dar ao processo de funcionamento da rádio. Quanto à escolha dos participantes e seu envolvimento na oficina, observa-se:

- Nas oficinas e nos grupos de discussão, Maria demonstrava mais habilidade em gerenciar as atividades. Não gostava de expor sua imagem ou voz, mas era habilidosa na arte de organizar, planejar, dirigir e controlar as produções. Por demonstrar essas habilidades, foi convidada a assumir o papel de roteirista e produtora-geral dos programas;

- Adele foi indicado para participar da oficina por ter computador e utilizar a música como meio de expressão. A equipe sugeriu que ele vivenciasse outros focos, outras experiências, aproveitando suas habilidades. Nas oficinas e nos grupos de discussão, Adele mostrava-se muito interessado em trabalhar com música e coletânea musical e sempre levava consigo o aparelho mp3 para compartilhar suas coleções. Nos horários livres, sempre estava com o aparelho ligado ao fone de ouvido. Adele não gostava de expor sua voz nas gravações. Como sugestão, ficou encarregado pela produção musical e pela edição da rádio;

- Sofia demonstrou interesse em aprender outras possibilidades de uso do computador e por mostrar uma boa receptividade às novidades. Sempre foi muito ativa e gostava de cantar, dublar e escrever durante as atividades. Assumiu a função de intérprete nos programas;

- Hades gostava de construir histórias em quadrinhos e queria conhecer outros dispositivos na internet. Verificada essa tendência, foi-lhe sugerida a oficina. O usuário costumava fazer imitação dos colegas e de personagens de desenhos animados. Foi feito o convite para que ele atuasse como o intérprete e editor de gravação.

$\mathrm{Na}$ oficina de Ambientação, as atividades, pela ótica dos usuários, iniciaram-se de fato com a apresentação dos equipamentos e da apropriação tecnológica. Os usuários aprenderam a montar e a desmontar o equipamento e utilizar Youtube e email. Na segunda parte do encontro, eles ficaram à vontade para se familiarizar com os computadores, sendo identificados e confirmados interesses e habilidades que cada usuário tinha no uso dos computadores. Sugeriu-se, então, a criação de um $b l o g$, como um espaço para registro e publicização das produções.

Era nítido o espanto de cada usuário ao verificar como ocorria o processo de mixagem e sonoplastia. À época, aproximava-se a Semana Santa, feriado em que é 
realizada a Paixão de Cristo. De iniciativa própria, Maria apontou a possibilidade de produzir uma radionovela sobre o assunto. Desde já, ficou combinado que cada usuário faria a pesquisa do texto original, que se encontra na Bíblia, e traria para que se pudesse discutir os fatos e montar o roteiro, planejar quais os recursos a utilizar, enfim, fazer o planejamento para a execução da radionovela. Uma vez conhecido um pouco da história do rádio no Brasil e a maneira ocorria a produção profissional no rádio brasileiro, com os aplicativos necessários à produção em rádio.

O software Audacity foi para eles a primeira experiência utilizando o editor de textos. Com o projetor ligado na parede frontal, cada usuário se achava conectado a um notebook com o software aberto. Foram demonstradas as funções de gravar, editar, mixar, salvar, aumentar e reduzir volume, inserir faixa adicional etc. Nessas atividades se destacaram Adele e Hades, conforme já era previsto. Eles utilizam computador próprio. Ao término do encontro, Adele trouxe algumas músicas que haviam sido solicitadas para a próxima produção da radionovela. Na saída da oficina, a mãe do Adele fez uma revelação em particular: "Esse é o encontro de que o "Adele" mais gosta... Logo cedo, ele já coloca o pendrive no pescoço e fica de um lado para o outro da casa, esperando dar a hora (14h) para chegar ao Caps... O que ele mais gosta é que vocês dão atenção a ele e ele consegue fazer as coisas de que gosta".

Decidiu-se ajudar na construção de um espaço para o Adele no grupo após se constatar seu interesse pela música e trabalhar no sentido de viabilizar essa potencialidade. No primeiro e no segundo encontro, tentou-se verificar as habilidades dos usuários e perceber o que eles tinham de melhor para oferecer, optando-se para que eles inicialmente trabalhassem com o que estava mais perto de sua realidade.

$\mathrm{Na}$ oficina para a produção da radionovela Paixão de Cristo, cada usuário havia feito a pesquisa e apresentado, de forma impressa ou por escrita, o relato dessa passagem bíblica. Discutiu-se o que trabalhar, pois a narração era muito extensa, e se pretendia fazer algo menor. Após longo conflito de ideias, ficou acertado que a parte a ser trabalhada seria a ressurreição de Cristo. Foi feita a divisão dos personagens de acordo com os interesses e aptidões de cada um. O pesquisador do projeto seria o narrador, Hades interpretaria Jesus e atuaria na edição; a colaboradora da pesquisa representaria Maria Madalena; Sofia Maria representaria a mãe de Jesus; já Adele representaria Tomé e atuaria como editor e produtor musical. Maria não participaria da representação, mas seria responsável pela direção e pela revisão do roteiro. Acertaram-se os detalhes antes de se começar a gravação propriamente dita e de serem apresentados os recursos utilizados.
A gravação foi iniciada e Adele assumiu de imediato o controle de edição no computador, através do Audacity. Todos se engajaram ativamente no projeto. Sofia revelouse muito capaz com os microfones, enfim, esteve muito à vontade nas gravações e cometeu poucos erros. Adele assumiu o papel de Tomé e surpreendeu a todos por sua participação efetiva. $\mathrm{O}$ grupo improvisou bem os efeitos da sonoplastia (choro, passos, suspiros). Aprenderam a construir de forma artesanal, na oficina prática, onde viram como eram produzidos esses efeitos.Depois de todas as falas gravadas, foi o momento crítico da edição. Todo o grupo, atento, buscou ajudar nesse processo. Foi acrescentada a trilha sonora e a conversão para o formato mp3. Depois disso, apreciou-se o resultado do trabalho. A produção foi muito positiva. Todos se encontraram nos modos de produção, modos de subjetivação e não mais sujeitos individuais, mas nos modos de interpretação, experimentação e construção da realidade, de si e do mundo (PASSOS; BENEVIDES, 2004).

$\mathrm{Na}$ oficina de produção do programa Momento de Poesia foi proposto pelos usuários um programa em que se trabalhasse a poesia. Logo se discutiu como seria o programa, como seriam produzidas as poesias. Maria intercedeu e sugeriu que poderiam ser produções próprias ou com as quais os usuários se identificassem. Cada usuário individualmente ficou em um computador, com o editor de texto aberto. A colaboradora e o pesquisador estiveram disponíveis para prestar auxílio aos usuários, caso necessário, mas poucos solicitaram ajuda, exceto no momento de salvar os arquivos. Como um dos produtos dessa oficina, Maria, ao produzir sua poesia, fez a interpretação de Eça de Queiroz:
Há corpos de agora, com almas de outrora.
Corpo é vestido.
Alma é pessoa.
(Eça de Queiroz)
Digitado por Maria
INTERPRETAÇÃO:
Este poema fala claramente da reencarnação.
Enquanto CORPO, este pede, reclama: água, agasalho ou mesmo alimentos.
Enquanto ALMA, esta sente: dor, angústia, satisfação, tristeza, alegria etc.

Todos os participantes trabalharam ativamente nessa produção. O produto final foram quatro poemas, alguns de autoria própria e outros de autores renomados da literatura brasileira. A oficina revelou a identificação deles com a poesia. Cada usuário trouxe como poema aquilo com que se identificava, suas escolhas pessoais.

$\mathrm{Na}$ oficina de produção do quadro de reportagens Você Sabia!, objetivou-se a aprendizagem do uso 
de dispositivos de pesquisas na internet para fins de construção de reportagens para rádio. No primeiro momento foram trabalhadas as modalidades de pesquisa com o uso do Google como fonte de pesquisa.

Maria foi a maior incentivadora desse programa porque, segundo ela, os usuários deveriam ser sempre informados com temas de relevância social. O grupo decidiu que o tema de pesquisa seria livre. A atividade poderia ser online ou na revista impressa, a depender do desejo do usuário. Já haviam sido providenciadas revistas atualizadas sobre diferentes temas, com reportagens e curiosidades. No total, havia oito revistas.

Hades iniciou redigindo e gravando. Sua reportagem partiu de sua experiência como usuário e da experiência vivida em família. Ele escreveu a seguinte reportagem:

Certo dia estava em casa quando vi mamãe desesperada procurando seu remédio tarja preta desesperada. Eu disse coroa vossa senhoria esta muito estressada. É porque eu não achei meu tarja preta. Eu disse vá fazer uma terapia em grupo e pare de tomar esse maldito remédio. Nem sempre é bom tomar remédio em vão. Tá ligado, coroa?

Maria também fez sua produção para a reportagem, que se baseou numa experiência particular, por isso não precisou utilizar fontes de pesquisa como as revistas e o computador conectado à internet. Ela tratou do tema solidão e redigiu a seguinte reportagem:

Quem sabe se o progresso do homem pode estar sendo o seu regresso? Com todos esses avanços tecnológicos as pessoas se sentem cada vez mais sós. E existe uma forma de compensar o que eles não têm, são os chamados sintomas. São eles: promiscuidade, gula, alcoolismo, uso de droga e até o suicídio.

\section{CAUSAS DA SOLIDÃO:}

Isolamento; condições de trabalho; comunicação fria; mudança de ambiente; morte de alguém querido; estar divorciado, separado ou solteiro; idade avançada e inexperiência da juventude.

SOLUÇÕES:

Ser simpático; não evitar as pessoas; ser otimista; ter autoestima; ter amigos; buscar a Deus.

\section{VENÇA A SOLIDÃO COM:}

Uma atitude positiva; evite tarefas só; faça amizades com almas afins, que podem ser de outra faixa etária; e, acima de tudo, eleve o pensamento, busque a Deus, seja caridoso, seja um fiel fervoroso e você verá a diferença.

Assim, a oficina começou trabalhando os mecanismos de pesquisa e terminou com os usuários gravando, editando e deleitando-se com suas respectivas produções. Ao final da produção, todos ouviram e ficaram alegres com os resultados do próprio trabalho. Naquele momento, eles haviam criado algo com que se identificavam.

A produção de subjetividade pode ser compreendida nesse caso como um processo de que os usuários foram partícipes diretos e protagonistas de seu próprio conhecimento (COSTA-ROSA, 2012). Ou seja, enquanto capacidade do sujeito de agir sobre si mesmo, através da interação consigo, com as tecnologias e com seus pares, numa construção inclusiva e social (COSTA, 2011). Os conflitos situacionais no coletivo provocaram desafios e interações que evidenciaram o amadurecimento individual e grupal. Juntos, nas situações vivenciadas, nos conflitos e nas produções pessoais e coletivas, ante os desafios vivenciais e aqueles que o mundo externo e o meio social externo lhes colocavam ao longo da jornada. Desafios que foram construtivos ao grupo e individualmente, a ponto de evidenciarem, mesmo que disso não se dessem conta, o despertar de habilidades sociais e emocionais que cada vez mais os identificavam com os outros. Conforme Pelbart (2003, p. 73):

Uma força viva, até mesmo uma potência política. Pois as forças vivas presentes na rede social, com sua inventividade intrínseca, criam valores próprios, e manifestam sua potência própria. É o que alguns chamam de potência de vida do coletivo, sua biopotência. É um misto de inteligência coletiva, afetação recíproca, produção de laço.

Assim, Maria, Hades, Sofia e Adele protagonizaram uma caminhada ímpar nessa intervenção que os fez desenvolver habilidades de autoaceitação e tolerância mútua, respeito e autonomia, sentimento de comprometimento, responsabilidade e pertencimento grupal. Essas características ficaram evidentes no fato da organização do grupo, que partia sempre de iniciativas de seus membros. Os temas e as formas de se fazer as produções eram sempre de indicação dos usuários. Maria, no início das oficinas demonstrava certo grau de isolamento do convívio social. Essa atitude a apartava das oficinas e, embora tenha declarado o desejo de aprender informática e outras coisas novas, não se permitia interagir com os grupos.

Foi identificado pelo pesquisador, no processo de observação participante, que Maria era uma boa observadora, conseguia ter uma visualização macro do grupo e, por sempre estar de fora, ficava sempre a observar o todo. Nas poucas interações que fazia no início do percurso, demonstrou habilidades gerenciais. Sempre bem organizada com seus pertences e atividades. A partir dessa percepção, o primeiro desafio foi superar a não aceitação social, ou seja, o sentimento de não pertencimento coletivo. Como não havia interesse em tomar parte com o uso da voz nas gravações dos 
programas, sua participação na produção geral dos programas foi essencial para a caminhada no coletivo. Conforme relata o técnico de referência: "Maria deu um salto qualitativo muito grande. Seu progresso nas oficinas tem sido evidenciado na elevação do grau de interação social e no grau de tolerância no convívio social”.

Segundo Alves e Guljor (2008), a participação em diversas atividades e inserções sociais é uma das premissas primordiais para o cuidado em saúde mental. A corroborar essa visão coletiva, Guattari (1992, p. 17) afirma que o constitutivo de subjetividades que prescindem do indivíduo precisa antes se "desdobrar num arquipélago de instâncias locais de subjetivação coletiva".

Hades apresentava-se introspectivo e com pouca participação no contexto social. Conforme observação feita pelo pesquisador, mostrava grande ansiedade em interagir na criação, mas se policiava nas participações. Percebeu-se que ele era criativo nos desenhos e imitações, e que possuía habilidades no uso do computador. Logo esse potencial foi aproveitado. Precisava-se de intérprete, e Hades possuía diversas vozes, por gostar de imitar oralmente outras pessoas. Foram também aproveitadas suas habilidades com o uso do computador. Ele foi corresponsável pela edição dos programas de rádio. Gravava, editava e publicava os programas. Sentia-se importante no grupo e deixava sempre isto claro ao cumprir com muita responsabilidade sua designação. A técnica de referência relata o progresso do usuário:

\begin{abstract}
A evolução do Hades é muito boa; ele já recebeu alta do Caps. Suas habilidades criativas foram expostas, ele sente-se mais seguro para criar e expor suas produções. Antes ele não tinha um espaço como este para produzir. Ele estava inserido em grupos que apenas trabalhavam mais a interação social, mas não desenvolvia mais que isso, não se realizava totalmente. Agora ele aprendeu a criar histórias e a gravar áudio, e o faz no seu próprio computador. Ele já faz suas artes e sente mais autonomia para produzir. O que tinha de ser aprimorado aqui no Caps já foi conseguido.
\end{abstract}

De fato, Hades não tinha um espaço em que pudesse realizar-se enquanto sujeito protagonista de sua arte, onde o social e suas habilidades pudessem aflorar. A inclusão do sujeito em ambientes digitais potencializou seu desenvolvimento social. As TICs na proposta de intervenção, nas oficinas no Caps, têm como um de seus objetivos possibilitar que os sujeitos envolvidos no processo reconheçam "suas potencialidades e responsabilidades, apropriando-se de forma criativa e diferenciada das tecnologias de rede, libertando-os de uma posição passiva" (FORESTI e TEIXEIRA, 2006, p. 6).

Sofia demonstrava ser uma garota tímida e reservada. Há algum tempo, ela se afastou do cotidiano social. Restringia seu convívio apenas à família e a poucos amigos. Demonstrava desejo de interagir com o computador. Aquela era uma caminhada nova e diferente. Tendo sido designada para as atividades de interpretação musical ou de personagens fictícios, sentiu-se integrada a uma atividade. Logo Sofia mostrou-se receptiva às propostas e atividades desenvolvidas. Sua técnica de referência afirmou:

Sofia vem relatando satisfação em participar das atividades. Reduziu significativamente a medicação, com possibilidade de ser retirado o uso. Já teve alta em algumas atividades pelo quadro de melhoras, mas não se afastou da oficina de informática por ser a principal atividade que tem se mostrado eficaz no seu processo de habilitação social. Aos poucos está recuperando a autonomia para sair e fazer atividades fora de casa e do Caps.

Bittencourt (2012) acrescenta que ajudar pessoas em sofrimento psíquico a resgatar o elo perdido com sua vida representa uma demonstração de valorização do ser humano e de respeito à sua história de vida. Essa valorização está representada no resgate de suas habilidades em potencial e em torná-las conhecidas, fazendo com que venha a ocorrer uma autoaceitação no cotidiano social.

Adele, por sua vez, demonstrava-se introspectivo e pouco comunicativo (monossilábico), com baixo comando de voz e autonomia limitada para realizar tarefas. A equipe priorizou no seu processo de habilitação social a socialização e a autonomia. Ele se limitou a ter amigos pela internet, passando boa parte do tempo online, em sites de redes sociais ou em repositórios de músicas. A equipe multiprofissional do Caps sugeriu sua presença no coletivo das oficinas, tendo em vista o aproveitamento de suas habilidades com o computador. Nas oficinas, Adele mostrava-se muito interessado em trabalhar com música, sobretudo com o processo de edição que utilizava o Audacity. Ele passou a atuar nas oficinas, usando o aplicativo, porém sem expor a voz nas gravações. Em certo momento, teve a iniciativa de fazer uma pequena participação e empolgou todo o grupo. Sua função principal no coletivo foi atuar como produtor musical e editor de áudio na rádio. Conforme relata seu técnico de referência: "O progresso de Adele foi estupendo. Sua entrada no coletivo das oficinas em rádio foi concomitante com a acolhida no Caps. Logo percebemos que ele voltou a se expressar verbalmente e a demonstrar certa autonomia em casa e nas atividades do Caps".

As oficinas não representam uma cura em si para o usuário da rede de saúde mental e não podem ser entendidas como uma busca nesse sentido. Devem ser vistas como um conjunto de estratégias que enfrentam o 
problema com uma visão crítica sobre os modos de ser do próprio tratamento e do usuário (ROTELLI, 1990). Nesse sentido, pode-se pensar que as TICs podem ser parceiras nesse processo, via inclusão digital.

\section{CONClusões}

Este trabalho sugere uma análise da produção radiofônica quanto à produção de inclusão digital. A proposta está inserida não apenas no fato de o usuário ter acesso ao computador conectado à internet com seus múltiplos dispositivos e interfaces, mas em saber como utilizar esses recursos para melhorar sua condição de vida e exercer sua cidadania no cotidiano social. Busca criar no indivíduo condições peculiares de se autodescobrir e se reinventar, de utilizar o meio digital como expansão de sua inteligência, pois as TICs figuram não somente como "terreno de objetos artificiais, mas como potência de artificialização da cognição, da inteligência" (KASTRUP, 1999, p. 183), da autonomia e do exercício da cidadania.

Desse modo, entende-se a interação entre os usuários e as tecnologias não como a solução de problema ou a busca incansável pela cura, porém como invenção de problemas, isto é, uma problematização que "leva à invenção de novas formas de conhecer, de novas regras de funcionamento cognitivo" (KASTRUP, 2000, p. 40), de novas formas de conhecer e interagir com o mundo. Observa-se que o produto final das oficinas não foram os programas em áudio, mas o processo de inclusão digital. Nesse sentido, o processo de habilitação social e inclusão digital no coletivo, por promover inquietação e descobertas, coloca a cognição $\mathrm{e}$ as habilidades sociais em movimento.

Dentre os apontamentos podem-se destacar aspectos positivos e negativos nesse caminhar. Nos negativos, ressaltam- as questões políticas, como a falta de programas mais efetivos que disponibilizem espaços ou ilhas digitais, dentro da rede de atenção à saúde mental, para o acesso, inclusão e aprendizagem dos usuários da rede. Salvo a experiência deste projeto, que com recursos próprios forneceu os equipamentos para o transcorrer das oficinas, são mínimos os recursos disponíveis para oficinas em diversos Caps no Estado de Alagoas, apesar de ser o acesso às TICs um direito de todos os usuários dos serviços de atenção à saúde mental no Brasil.

Se o objetivo é enquadrar os usuários do serviço substitutivo no seio da sociedade, e se essa sociedade está ancorada no amadurecimento das TICs, seria plausível que o processo de habilitação social dos usuários dos serviços de atenção à saúde mental contemplasse ações de inclusão digital. Isso porque "inserir as pessoas em sofrimento psíquico no meio informatizado, na cultura e na sociedade, quebrando fronteiras e barreiras com os preconceitos, possibilita que essas pessoas se sintam incluídas no mundo contemporâneo" (FRANCISCO; RENZ, 2010, p. 2).

Como destacado por Bittencourt (2012), o conjunto de atividades deve, em sua aplicação e incorporação ao processo de habilitação, possuir relevância política, social, tecnológica e terapêutica por constituir alternativas de intervenção em saúde mental. Deve permitir atividades expressivas que apontem possibilidades do amadurecimento da autonomia social do sujeito, melhorem sua autoestima e o reponham em seu contexto social como protagonista de sua própria existência, com suas potencialidades reconhecidas pelos seus pares.

Ao longo dos meses em que as oficinas foram realizadas no Caps, verificou-se que, por mais simples que pareçam ser as atividades, no sentido da apropriação da técnica, a diferença reside na interação social, na valorização das capacidades do indivíduo, na criação de espaço que potencialize a criatividade e a cognição. E para que se conceda ao sujeito a oportunidade de protagonizar suas escolhas e de aprender a conviver com seus conflitos e vicissitudes, na perspectiva da inclusão digital.

Da mesma forma, o pedagogo pode ocupar outros campos para além da escola, pois as práticas educativas cada vez mais se fazem necessárias em empresas, ONGs sindicatos, hospitais, clínicas e, é claro, no campo da saúde mental. Conforme já foi discutido, a Pedagogia pode estar presente na saúde mental e o pedagogo pode cumprir, da mesma forma que na escola (mudando, é claro, o público, o contexto e os objetivos), funções estratégicas, de planejamento, organização e implementação de projetos, nos Caps e hospitais psiquiátricos. Pode trabalhar tanto na busca da reinserção social, parceria com as famílias e socialização do sujeito quanto no desenvolvimento de oficinas terapêuticas, abordando temas não apenas nas áreas de artes e tecnologias, como exemplificado nesta pesquisa. Mas explorando diversos outros, desde que se utilizem destes para a promoção da saúde mental.

Embora a presença do pedagogo ainda seja escassa nesse campo, as contribuições profissionais podem ser significativas. No entanto, faz-se necessário que espaços sejam abertos, que os profissionais estejam em constante pesquisa e aperfeiçoamento e dispostos a desenvolver seu trabalho com o máximo de seriedade e comprometimento.

\section{REFERÊNCIAS}

ALVES, Domingos Sávio; GULJOR, Ana Paula. O cuidado em saúde mental. In: PINHEIRO, Roseni; MATTOS, Ruben (Org.). Cuidado: as fronteiras da integralidade. Rio de Janeiro: CEPESC/UERJ/ABRASCO, 2008.

BARROS, Rafael André de. Saúde mental e webrádio: criando laços no Caps Jatiúca. 2012. 115 f. Dissertação (Mestrado em Educação) - Faculdade de Educação, Universidade Federal de Alagoas, Maceió, 2012. 
BARROS, Regina; PASSOS, Eduardo. A construção do plano da clínica e o conceito de transdisciplinaridade. Psicologia: Teoria e Pesquisa, v. 16, n. 1, p. 71-79, 2000. http://dx.doi. org/10.1590/S0102-37722000000100010.

BITTENCOURT, Ivanise Gomes de Souza. O processo de habilitação psicossocial de pessoas em sofrimento psíquico na interface com produção em blog. 2012. $116 \mathrm{f}$. Dissertação (Mestrado em Educação) - Faculdade de Educação, Universidade Federal de Alagoas, Maceió, 2012.

BRASIL. Lei 10.216/2001 de 06 de abril de 2001. Dispõe sobre a proteção e os direitos das pessoas portadoras de transtornos mentais e redireciona o modelo assistencial em saúde mental. Disponível em: <http://www.planalto.gov.br/ccivil_03/leis/ leis_2001/110216.htm>. Acesso em: 30 abr. 2014.

BRASIL. Resolução CNE/CP n ${ }^{\circ}$ 1, de 15 de maio de 2006. Dispõe sobre as Diretrizes Curriculares Nacionais para o Curso de Graduação em Pedagogia, licenciatura. Diário Oficial da União, Brasília, 16 de maio de 2006, Seção 1. Disponível em: $<$ http://portal.mec.gov.br/cne/arquivos/pdf/rcp01 06.pdf>. Acesso em: 29 abr. 2014.

COSTA-ROSA, Abílio da. A instituição de saúde mental como dispositivo social de produção de subjetividade. Estudos de Psicologia I Campinas, v. 29, n. 1, p. 115-126, 2012.

COSTA, Diogo Faria Corrêa da. Loucos para prot (agonizar): micropolítica e participação em saúde Mental. 2011. 111 f. Dissertação (Mestrado em Psicologia Social) - Faculdade de Psicologia, Universidade Federal do Rio Grande do Sul, Porto Alegre, 2011.

COSTA, Rosa Maria Moreira; CARVALHO, Luis Alfredo de. A realidade virtual como instrumento de inclusão social dos portadores de deficiências neuropsiquiátricas. In: SIMPÓSIO BRASILEIRO DE INFORMÁTICA NA EDUCAÇÃO, 14, 2003, Rio de Janeiro. Anais do XIV Simpósio Brasileiro de Informática na Educação. Rio de Janeiro: UFRJ, 2003. p. 431-440.

DELGADO, P.; LEAL, E.; VENÂNCIO, A. O campo da atenção psicossocial. CONGRESSO DE SAÚDE MENTAL DO ESTADO DO RIO DE JANEIRO, 1, 1997, Rio de Janeiro. In: Anais do I Congresso de Saúde Mental do Estado do Rio de Janeiro. Rio de Janeiro: Te Corá/Instituto Franco Basaglia, 1997. p. 85-94.

FORESTI, Andressa; TEIXEIRA, Adriano Canabarro. As potencialidades de processos de autoria colaborativa na formação escolar dos indivíduos: aprofundando uma faceta do conceito de inclusão digital. RENOTE - Revista Novas Tecnologias na Educação, v. 4, n. 2, p. 1-10, 2006.

FRANCISCO, Deise Juliana. Criando laços via recursos informatizados. 2007. 172 f. Tese (Doutorado em Informática na Educação), Universidade Federal do Rio Grande do Sul, Porto Alegre, 2007.

FRANCISCO, Deise Juliana; RENZ, Juliana Pacheco. Relação homem-máquina: pessoas em sofrimento psíquico e recursos digitais. SCIENTIA PLENA, v. 6, n. 11, p. 1-9, 2010.

GORCZEVSKI, Deisimer; PALOMBINI, Analice de Lima; STREPPEL, Fernanda Fontana. Entre improvisos e imprevistos: os modos de comunicar potência mental. In: ENCONTRO NACIONAL DA ABRAPSO, 15. 2009, Maceió. Anais do XV Encontro Nacional da ABRAPSO. Maceió, 2009.
GUATTARI, Félix. Caosmose: um novo paradigma estético. Rio de Janeiro: Ed. 34, 1992.

KASTRUP, Virgínia. A invenção de si e do mundo: uma introdução do tempo e do coletivo no estudo da cognição. Campinas: Papirus, 1999.

KASTRUP, Virgínia. Novas tecnologias cognitivas: o obstáculo e a invenção. In: KASTRUP, Virgínia; PELLANDA, Nize Maria; PELlANDA, Eduardo (Org.). Ciberespaço: um hipertexto com Pierre Lévy. Porto Alegre: Artes e Ofícios, 2000. p. 38-54.

LAPPANN-BOTTI, Nadja Cristiane. Oficinas em saúde mental: história e função. 2004. 244 f. Tese (Doutorado em Enfermagem Psiquiátrica) - Escola de Enfermagem de Ribeirão Preto, Universidade de São Paulo, São Paulo, 2004.

PASSOS, Eduardo; BENEVIDES, Regina. Clínica, política e as modulações do capitalismo. Revista Lugar Comum, Rio de Janeiro, n. 19-20, p. 159-171, jan.-jun. 2004.

PAULON, Simone Mainieri. A análise de implicação como ferramenta na pesquisa-intervenção. Psicologia \& Sociedade, v. 17 , n. 3, p. 18-25, set.-dez. 2005. Disponível em: < http:// www.scielo.br/pdf/\%0D/psoc/v17n3/a03v17n3.pdf>. Acesso em: 13 jan. 2012.

PITTA, Ana. O que é reabilitação psicossocial no Brasil, hoje? In: PITTA, Ana (Org). Reabilitação psicossocial no Brasil. São Paulo: Hucitec, 1996. p. 19-30.

ROLDÃO, Ivete Cardoso do Carmo; MOREIRA, Reginaldo. Um jornalista na loucura, despertando loucos por jornalismo. In: MERHY, Emerson Elias; AMARAL, Heloísa (Org.). A Reforma Psiquiátrica no Cotidiano II. São Paulo: Aderaldo \& Rothschild, 2007. p. 67- 81.

ROTELLI, F. Desinstitucionalização, uma outra via: a reforma psiquiátrica italiana no contexto da Europa Ocidental e dos "países avançados". In: Nicácio, F. (Org.). Desinstitucionalização. São Paulo: Hucitec, 1990.

SIMONDON, Gilbert. Du mode d'existence des objets techniques. Paris: Aubier, 1980.

STREPPEL, Fernanda. Devir-loucura no rádio. 2010. Dissertação (Mestrado em Psicologia Social e Institucional) - Universidade Federal do Rio Grande do Sul, Porto Alegre, 2010.

TEIXEIRA, Adriano Canabarro. Inclusão digital: novas perspectivas para a informática educativa. Ijuí, RS: Ed. Unijuí, 2012.

VENTURINI, Ernesto et al. Habilitar-se em saúde mental: observações críticas ao conceito de reabilitação. Arquivos Brasileiros de Psicologia, v. 55, n. 1, p. 56-63, 2003. Disponível em: <http://pepsic.bvsalud.org/pdf/arbp/v55n1/v55n1a07.pdf>. Acesso em: 10 jan. 2012.

\section{NotA}

1 Os nomes dos usuários foram modificados por pseudônimos, sendo que
cada um escolheu o seu, pelo qual é identificado neste trabalho.

Artigo recebido em setembro 2015.

Aprovado em novembro 2015. 